\title{
UM ESTUDO SOBRE A LEITURA E A INTERPRETAÇÃO DE TEXTOS EM MANUAIS DIDÁTICOS
}

\author{
A STUDY ABOUT READING AND INTERPRETATION OF TEXTS IN TEXTBOOKS
}

\author{
Viviane Netto Silva \\ Universidade Federal de Minas Gerais
}

RESUMO: Este artigo apresenta dados de uma pesquisa realizada no âmbito do programa de Mestrado em Estudos Linguísticos na Universidade Federal de Minas Gerais (UFMG). Buscaremos refletir sobre como se dá o trabalho de leitura e interpretação de textos em manuais didáticos de língua materna portuguesa e italiana, tendo como foco específico a análise das perguntas sobre os textos para leitura. Como teoria de base temos a Análise do Discurso de linha francesa acrescida da contribuição de outros autores que enriqueceram o estudo.

PALAVRAS-CHAVE: Livro didático; Ensino; Análise do Discurso.

ABSTRACT: This article presents results of the research which was conducted under the auspices of the Master Program in Linguistics at Universidade Federal de Minas Gerais (UFMG). The work intends to reflect about the study with reading and interpretation of texts in Portuguese and Italian mother-tongue textbooks focusing in the analysis of the questions about reading texts. This study is based upon the French Speech Analysis complemented with the contributions of other authors that enriched the study.

KEY WORDS: Textbook; Teaching; Speech Analysis.

Introdução

A realização do presente trabalho partiu da observação dos resultados de algumas avaliações sobre a educação no Brasil, resultados esses que causaram muito impacto em nossa sociedade ao revelarem o baixo desempenho dos nossos alunos no que se refere às atividades de leitura e interpretação de textos. Por exemplo, os dados do Sistema de Avaliação da Educação Básica (SAEB) de 2001 comprovam que a grande maioria dos alunos do ensino fundamental conclui essa etapa sem as habilidades mínimas esperadas em várias das disciplinas cursadas, dentre elas Língua Portuguesa. No que diz respeito às provas que avaliam a performance dos alunos em análise de textos, o SAEB explicita que em itens como: 1) identificar os elementos que constroem as narrativas; 2) compreender a estrutura argumentativa de textos; 3) reconhecer diferentes formas de tratar a informação na comparação de textos sobre o mesmo tema; os índices de acertos obtidos foram muito abaixo do esperado (inferiores a $60 \%$ ). 


\section{Revista do SELL}

v. $4, n^{\circ} .1$

ISSN: $1983-3873$

Tal resultado se aproxima muito dos dados fornecidos pelo Programa Internacional de Avaliação de Alunos (PISA), aplicado no ano 2000, que indicam que a maior concentração dos estudantes brasileiros permaneceu no nível 1, ou abaixo dele, na escala geral de leitura subdividida em cinco níveis de proficiência. Isso significa que eles são capazes apenas de localizar informações explícitas no texto e fazer conexões simples entre enunciados. Um desempenho equivalente foi obtido na segunda versão da pesquisa (2003). Já em 2006, a situação agravou-se: o Brasil obteve o pior resultado em relação às demais versões.

Uma análise mais profunda desse exame permitiu-nos verificar que as médias obtidas pelos alunos brasileiros em leitura, em relação aos demais países - sobretudo os ditos de Primeiro Mundo -, estão entre as piores. Tomando por base esse quadro e considerando que o livro didático continua sendo um dos pilares do processo de ensino/aprendizagem, chegamos às seguintes questões: como se constroem as atividades de interpretação de textos em manuais didáticos de nações do Primeiro Mundo? Como elas seriam elaboradas, por outro lado, em manuais de países em desenvolvimento, como o Brasil? Quais seriam as semelhanças e diferenças relacionadas ao modelo de ensino de leitura adotado nesses países e ao perfil do aluno-leitor que subjaz a esse modelo?

Tais indagações motivaram-nos a realizar uma análise contrastiva do discurso de manuais didáticos italianos e brasileiros. Os livros selecionados para a pesquisa foram: Português: Linguagens, $7^{a}$ série- $8^{\circ}$ ano (CEREJA; MAGALHÃES, 2002) e La lampada di Aladino 2 (MANDELLI; ROVIDA, 2000). A escolha do manual italiano se justifica pelo domínio da língua pela pesquisadora, formada nas habilitações Português-Italiano pela UFMG, e pelo intuito de dar continuidade a uma pesquisa, iniciada na Itália em 2006, sobre o uso de manuais didáticos de língua materna em escolas italianas.

A partir dos resultados dos sistemas de avaliação apresentados anteriormente, nossa hipótese de partida é a de que as estratégias de ensino e as atividades de leitura propostas pelo manual italiano seriam mais eficazes se comparadas às do manual brasileiro. Uma segunda hipótese que levantamos é a de que as competências requeridas dos alunos brasileiros, durante os trabalhos com a leitura na escola, são inadequadas para o desenvolvimento do seu raciocínio crítico. Essa hipótese segue a mesma direção das pesquisas de Dell'Isola (1991) e Matêncio (2001), que apontam para a necessidade 


\section{Revista do SELL}

v. $4, n^{\circ} .1$

ISSN: $1983-3873$

de uma revisão dos procedimentos adotados nas atividades de leitura em sala de aula, as quais esteiam-se, principalmente, no livro didático.

Dell isola (1991, p. 198) afirma que nossas escolas tomam como padrão o modelo inferencial da classe dominante. Diante dessa situação "os alunos da classe alta e médiaalta interpretam um texto, dele extraindo as inferências adequadas ao contexto sóciocultural em que vivem". O que se espera dos alunos de classe média-baixa e baixa "que aprendam a maneira de pensar, a interpretação desejada pelo modelo que a escola fixou como correto" sendo que "o que foge do padrão é incorreto, é condenado". Na perspectiva da autora, esse modelo desconsideraria a forma particular de pensar, o raciocínio, dos alunos de classe média-baixa e baixa, privilegiando, assim, as elites.

Na mesma direção de Dell isola, ao realizar um levantamento dos diversos trabalhos sobre o ensino de Língua Materna no Brasil, Matêncio (2001, p. 33-34) assevera que as pesquisas demonstram "que as dificuldades apresentadas pelos alunos (...) são resultado da ausência de um trabalho que redimensione o texto em sala de aula e o relacione a situações efetivas de uso da língua" e também que "a linguagem da escola não é a do aluno". Pelos dizeres de Matêncio (2001) observamos uma necessidade de reestruturação da escola, de forma que as atividades propostas em sala de aula se aproximem do universo quotidiano do aprendiz, e despertem neles a capacidade de análise e reflexão, em detrimento à mera decodificação e cópia.

As constatações feitas por essas autoras levam-nos a crer que, a partir da observação do modo como a leitura é trabalhada nos manuais, podemos identificar que tipo de formação está sendo oferecida pela instituição escolar. Assim, nossa preocupação central será investigar a(s) imagem(ns) do aluno-leitor projetada(s) nos dois manuais didáticos mencionados - um brasileiro e um italiano - e, mais especificamente, analisar, no que se refere às atividades de leitura propostas, como se constroem as perguntas e as asserções sobre os textos dados para leitura e como elas norteiam o trabalho a ser desenvolvido em sala de aula. Para tanto, utilizaremos as contribuições teóricometodológicas da Análise do Discurso, acrescidas de alguns conceitos postulados por outros teóricos que acreditamos ser proveitosos para enriquecer a análise. Em um primeiro momento apresentaremos a metodologia que será utilizada para a realização da pesquisa. Passaremos, no próximo item, aos pressupostos teóricos e à análise dos manuais. 


\section{Revista do SELL}

v. $4, n^{\circ} .1$

ISSN: $1983-3873$

Questões metodológicas: os livros escolhidos e os critérios de seleção

Conforme afirmamos anteriormente, para compor o corpus desta pesquisa selecionamos dois manuais didáticos de língua materna: um brasileiro: Português: Linguagens, $7^{a}$ série- $8^{\circ}$ ano (CEREJA; MAGALHÃES, 2002); e outro italiano: La lampada di Aladino 2 (MANDELLI; ROVIDA, 2000), com o objetivo maior de contrastar as atividades de leitura propostas por cada um deles, considerando-se a distância no desempenho dos alunos brasileiros e italianos em avaliações de desempenho.

O principal critério para a escolha do livro brasileiro foi sua utilização em sala de aula. Uma enquete informal realizada em livrarias de Belo Horizonte, tais como Leitura, Nossa Livraria e Ouvidor, permitiu-nos constatar que o livro de Cereja e Magalhães é muito usado nas instituições privadas. Além disso, como ele faz parte do catálogo de livros sugeridos pelo Programa Nacional do Livro Didático (PNLD) do ano de 2008, sua utilização tem sido grande também em escolas públicas.

O manual italiano, por sua vez, tem sido adotado tanto em escolas bilíngues de Belo Horizonte, como a Fundação Torino, quanto em escolas italianas, conforme informações obtidas através do acesso ao site do Ministério da Educação da Itália e também pela própria editora. Além do critério da utilização em sala de aula, observamos também a equivalência nos graus de ensino dos dois países. A $7^{\text {a }}$ série no Brasil (atual $8^{\circ}$ ano) corresponde ao segundo ano da scuola media na Itália, e a faixa etária e o número de anos em que os alunos frequentam a escola não apresentam divergências. No item seguinte apresentaremos o quadro teórico de nossa investigação.

Pressupostos teóricos: um olhar sobre as marcas de heterogeneidade nos discursos

Em nossa pesquisa, buscaremos contemplar o aspecto dialógico/enunciativo das perguntas e asserções sobre os textos de leitura dos livros didáticos, por meio das noções de paráfrase e pressuposição, que se configuram como marcas de heterogeneidade discursiva. Dentre os pesquisadores que vêm utilizando a noção de heterogeneidade em seus trabalhos, destaca-se Maingueneau (1997, p. 75) que, na esteira de Authier-Revuz (1998), reconhece que há dois planos distintos, mas complementares, de heterogeneidade: a constitutiva e a mostrada. 


\section{Revista do SELL}

v. $4, n^{\circ} .1$

ISSN: $1983-3873$

O autor afirma que a heterogeneidade mostrada "incide sobre as manifestações explícitas, recuperáveis a partir de uma diversidade de fontes da enunciação" (MAINGUENEAU, 1997, p. 75). Os fenômenos a ela relacionados ultrapassam a noção tradicional de citação e de discurso relatado, abrangendo também os conceitos de parafrasagem, de negação, de pressuposição etc.

Esse tipo de heterogeneidade pode ser marcada (por meio de elementos linguísticos ou tipográficos) ou não (em fenômenos como a ironia ou o discurso indireto livre). Podemos dizer que ela representa o encontro do enunciador com um dizer externo ao seu discurso. Já a heterogeneidade constitutiva "aborda uma heterogeneidade que não é marcada em superfície, mas que a $A D$ pode definir, formulando hipóteses, através do interdiscurso, a propósito da constituição de uma formação discursiva" (MAINGUENEAU, 1997, p. 75).

Conforme afirmamos, em nosso estudo examinaremos as paráfrases e a pressuposição, que são fenômenos da heterogeneidade mostrada (marcada), e respondem pela forma como as perguntas e asserções sobre os textos lidos são construídas pelo locutor. Elas nos revelam, assim, o perfil esperado do aluno-leitor. Veremos a seguir algumas de suas características.

Explorando o discurso e suas "vozes": a paráfrase e a pressuposição

O fenômeno da paráfrase

Os estudos atuais sobre o fenômeno da paráfrase têm se desenvolvido, conforme Fuchs (apud RIBEIRO, 2002, p. 2), a partir de três perspectivas teóricas. Na primeira, a paráfrase é tomada como uma equivalência formal entre as frases e é baseada em postulados lógicos. Já na segunda vertente, tendo em vista alguns critérios semânticos entre os enunciados, ela é compreendida a partir de uma relação de sinonímia. $\mathrm{Na}$ terceira perspectiva, por sua vez, a paráfrase é tomada como uma atividade de reformulação, pois sofre mudanças de acordo com os sujeitos e os contextos em que são produzidas. Nessa terceira vertente, na qual a autora se apóia se enquadram pelo menos três abordagens teóricas distintas: pragmática, discursiva e enunciativa.

Conforme Fuchs (apud PETIT, 2004, p. 366) a paráfrase não pode provir de uma relação de sinonímia, pois "convida à deformabilidade do sentido em discurso". 


\section{Revista do SELL \\ v. $4, n^{\circ} .1$ \\ ISSN: $1983-3873$}

Concordando com a autora, Ribeiro (2002, p. 1) explicita que parafrasear nem sempre significa estipular sentidos, mas sim abrir-se à possibilidade do novo. Nessa mesma direção, Petit (2004, p. 366) aponta que a paráfrase "é uma relação de equivalência entre os enunciados, um deles podendo ser, ou não, a reformulação do outro".

A partir dos dizeres desses autores, podemos notar que a atividade de parafrasear está relacionada a uma atividade dos parceiros do ato comunicativo. Tais parceiros constroem e re-constroem os diferentes sentidos dos enunciados, reformulam constantemente os dizeres externos a seu discurso e, conforme Ribeiro (2002, p. 1), estão explicitamente engajados em um processo discursivo.

Por não apresentarem nenhuma neutralidade, por não refletirem apenas sentidos contidos em dicionários, as paráfrases são consideradas, na ótica de Maingueneau (1997, p. 97), fatos discursivos. Conforme o autor, na vertente da AD (ou da ADF, na perspectiva que estamos assumindo aqui), o que interessa são as paráfrases produzidas pelo próprio locutor que, na posição de "enunciador autorizado", não se contenta somente em dizer, mas quer mostrar-se como alguém capaz de dominar os signos. Porém, sendo reguladas pelas coerções de uma formação discursiva, as paráfrases podem, na verdade, ser tomadas como uma tentativa, empreendida pelo locutor, de controlar, em pontos nevrálgicos, a polissemia aberta pela língua e pelo interdiscurso. (MAINGUENEAU, 1991, p. 147-148)

Ao empregar fórmulas do tipo: isto quer dizer, ou seja e similares, o locutor realiza uma operação metadiscursiva que serve para identificar, no discurso, dois termos $-\mathrm{X}$ e $\mathrm{Y}$ -cuja equivalência não é instituída pela língua. Em um certo sentido, a paráfrase bloqueia a infinidade de possíveis interpretações de um determinado termo ou ideia, fornecendo um equivalente que, ao invés de explicitar um sentido único, garantido por um determinado saber, o constrói em sua própria enunciação (MAINGUENEAU, 1991, p. 148). No item seguinte observaremos as peculiaridades da segunda marca de heterogeneidade de nosso estudo: a pressuposição.

O fenômeno da pressuposição

Estudaremos o fenômeno da pressuposição a partir da proposta de Ducrot (1987), e de outros autores que nele se baseiam. Ducrot desenvolveu o que chamou de "esboço de uma teoria polifônica da enunciação" no seu livro $O$ dizer e o dito (edição 


\section{Revista do SELL \\ v. $4, n^{\circ} .1$ \\ ISSN: $1983-3873$}

brasileira: 1987), no quadro da semântica argumentativa. Buscaremos 1) conceituar o fenômeno; 2) analisar suas principais propriedades; 3) explicitar suas funções em meio ao universo discursivo. No âmbito da teoria polifônica da enunciação, Ducrot toma o pressuposto como

uma evidência, como um quadro incontestável no interior do qual a conversação deve necessariamente inscrever-se, ou seja, como um elemento do universo do discurso. Introduzindo uma ideia sob forma de um pressuposto, procedo como se meu interlocutor e eu não pudéssemos deixar de aceitá-lo. (DUCROT, 1987, p. 20)

Seguindo essa direção, Kerbrat-Orecchioni (2004, p. 404) afirma que os pressupostos correspondem a realidades supostamente já conhecidas do sujeito destinatário, a "evidências partilhadas ou fatos decorrentes de seus saberes prévios". Como assevera Lara (2009, p.6), nessa perspectiva, "embora os pressupostos possam ser questionados e mesmo negados, eles são feitos para não o serem".

A partir dos dizeres desses autores, notamos que os pressupostos não permitem ao destinatário do discurso a recusa, a negação e nem mesmo a dúvida sobre os dados que Ihe foram, implicitamente, apresentados. Assim, ao co-enunciador não é dada qualquer possibilidade de escolha no decorrer da troca comunicativa: ele é colocado em situação de falta de liberdade, pois, se nega os pressupostos, impede a própria continuação do diálogo. Cabe ressaltar que, na perspectiva da ADF, essa aceitação - ou ausência de questionamento - do conteúdo pressuposto ocorre apenas se o leitor estiver inscrito na mesma formação discursiva ${ }^{1}$ do locutor.

Por serem autônomos e se manifestarem independentemente do contexto enunciativo, os pressupostos se distinguem de um segundo tipo de conteúdo implícito: os subentendidos. Conforme Ducrot (1987, p. 41), no quadro teórico da semântica argumentativa, enquanto os pressupostos são conteúdos internos aos enunciados, que constringem o destinatário a assimilar um sentido que lhe é imposto como único, os subentendidos são relacionados à atividade de decodificação e interpretação dos sujeitos.

\footnotetext{
${ }^{1}$ Em nosso trabalho, tomamos o conceito de formação discursiva sob a ótica de Pêcheux. O autor designa as formações discursivas como "aquilo que numa formação ideológica dada, isto é, a partir de uma posição dada numa dada conjuntura, determinada pelo estado de luta de classes, determina o que pode e deve ser dito". (PÊCHEUX, 1988, p. 160). As formações discursivas constituem uma noção-chave para a $\mathrm{AD}$ por "reconhecerem a existência de várias linguagens em uma única" e serem heterogêneas, ou seja, não estabelecerem "um limite rigoroso entre seu interior e exterior”. (BRANDÃO, 2004, p. 88-89).
} 


\section{Revista do SELL}

v. $4, n^{\circ} .1$

ISSN: $1983-3873$

Hoje em dia, presenciamos uma discussão acerca da seguinte problemática: quais propriedades podem ser atribuídas aos pressupostos? É possível organizar uma proposta única de categorização para eles? Segundo Kerbrat-Orecchioni (2004, p. 404), a principal dificuldade em distinguir o vasto conjunto de pressupostos se encontra nos seguintes fatores: 1) eles se prestam a inúmeras formas de "manipulações"; 2) nem todos os tipos se comportam da mesma forma. Todavia, destaca a autora, em um ponto específico existe um consenso entre as vertentes teóricas: os pressupostos constituem conteúdos marcados em um discurso.

Comentando as funções dos pressupostos no universo discursivo, Koch (2000) constata a existência de uma "retórica da pressuposição". Trata-se, segundo ela, de um recurso argumentativo bastante comum em nosso cotidiano, que consiste em apresentar "como se fosse pressuposto justamente aquilo que se está querendo veicular como informação nova". (KOCH, 2000, p. 45 - grifo da autora). Desse modo, enunciados do tipo "lamentamos não aceitar cheques", ou "lamentamos não poder atender à sua solicitação" - encontrados em estabelecimentos comerciais, postos de gasolina etc. - podem servir como uma forma de "atenuação", como uma ferramenta para veicular, de maneira cordial ou branda, uma informação que não é de interesse do receptor. Neste item nos detivemos na apresentação do quadro teórico do qual nos servimos para a realização da pesquisa, acrescido da contribuição de outros autores que enriqueceram o estudo. Como pudemos observar, para o estudo do fenômeno da pressuposição tanto analistas do discurso, como outros teóricos, "importaram" as valiosas contribuições de Ducrot, e de seu quadro teórico da semântica argumentativa. Veremos, adiante, como as marcas de heterogeneidade elencadas acima se manifestam no corpus selecionado.

Identificação e exame das marcas de heterogeneidade do discurso

Neste item, lançaremos nosso olhar para a forma como se constroem as asserções e perguntas sobre os textos dados para leitura nos manuais selecionados. Tomaremos como foco de análise algumas marcas da heterogeneidade mostrada: a paráfrase e a pressuposição. Esses fenômenos nos permitem apreender as relações estabelecidas entre as instâncias envolvidas: o locutor (autor do manual), seu próprio dizer, o interlocutor (aluno-leitor) e um discurso terceiro, desvinculado tanto do locutor quanto do interlocutor, que pode fazer-se presente no dispositivo didático. Com isso, acreditamos 


\section{Revista do SELL}

v. $4, n^{\circ} .1$

ISSN: $1983-3873$

poder identificar as competências requeridas dos alunos durante os trabalhos de leitura e, a partir delas, apreender a(s) imagem(ns) do aluno-leitor construída(s) nos manuais selecionados, objetivo de nossa pesquisa.

A manifestação das paráfrases nos manuais didáticos

Em nossa pesquisa pudemos notar, assim como Lara (1999, p. 162), que as paráfrases são veiculadas com bastante frequência no discurso didático (ou, mais especificamente, no discurso do livro didático, nosso objeto de pesquisa). Na investigação das asserções e perguntas sobre os textos de leitura nos manuais, detivemos nosso olhar especificamente sobre as paráfrases formuladas pelo locutor, que instituem uma relação de equivalência no interior da própria enunciação - relação essa que não é dada a priori. Observemos os exemplos dos manuais Português: Linguagens, doravante PL :

ex.1) Q.4-A linguagem pode ser compreendida como expressão da identidade do ser humano, ou seja, ela é o meio que utilizamos para expressar o que somos. (PL, 2002, p. 145)

ex.2) Q.1- Epígrafe é uma citação - ou seja, um trecho da obra de outro autor - que serve de tema ou inspiração para determinada obra que se inicia. Compare as epígrafes ao poema de Carlos Drummond de Andrade: (PL, 2002, p. 208)

ex.3) Q.5- Ao produzirmos um texto, a escolha de certos vocábulos revela uma apreciação avaliativa, isto é, a posição que temos diante do tema enfocado. Identifique nesse trecho palavras e expressões que demonstrem uma posição crítica do eu lírico diante do fim de Sete Quedas. (PL, 2002, p. 208)

Nesses enunciados podemos notar que a interpretação dos termos dados é construída no próprio discurso do locutor, que assume a posição de "enunciador autorizado". Observamos que essas paráfrases não são neutras - não apresentam 


\section{Revista do SELL}

v. $4, n^{\circ} .1$

ISSN: $1983-3873$

sentidos contidos em dicionários - e marcam a tentativa do locutor de controlar a polissemia aberta pela língua. (MAINGUENEAU, 1991, p. 147-148)

No que se refere às funções dessas paráfrases no discurso do locutor (os autores do manual tomados em conjunto), notamos, nos exemplos 2 e 3 , uma tentativa de apresentar os termos "citação" (que, por sua vez, retoma epígrafe) e "avaliação apreciativa" em uma linguagem mais próxima da dos aprendizes, tornando mais fácil a apreensão de seus significados. Esse aprendiz, por sua vez, deverá aceitar a equivalência proposta para poder continuar o diálogo. Assim, se no exemplo1, ele discordar que o enunciado "a linguagem pode ser compreendida como expressão da identidade do ser humano" seja o mesmo que "ela [a linguagem] é o meio que utilizamos para expressar o que somos" não será possível dar continuidade à atividade proposta. Isso quer dizer que o aluno até pode não aceitar a equivalência proposta na/pela questão, mas ela é feita para não ser contestada.

Os exemplos acima nos mostram que o interlocutor deve concordar com o posicionamento do locutor, com o "contrato" estabelecido entre eles; do contrário a comunicação tende a falhar. Vejamos, a seguir, as paráfrases apresentadas no manual italiano La Lampada di Aladino (2000), doravante LA:

ex.4) Q.2- II gatto era "vivo soltanto perché era stato capace di usare il proprio ingegno", cioè era riuscito a farsi capire e accettare dagli esseri umani. (LA, 2000, p. 596) (O gato estava "vivo somente porque tinha sido capaz de usar a própria inteligência", isto é, conseguiu fazer-se entender e ser aceito pelos seres humanos.

ex.5) Q.2- Evidenzia i passi in cui il testo di questa seconda lettera diventa "lirico", esprime cioè immagini e pensieri che appartengono più alla poesia che alla prosa. (LA, 2000, p. 596) (Evidencie as passagens nas quais o texto dessa segunda carta torna-se "lírico", ou seja exprime imagens e pensamentos que pertencem mais à poesia do que à prosa.)

Podemos notar que essas paráfrases estabelecem uma relação de equivalência entre dois enunciados ou termos, buscando induzir, de certa forma, a interpretação do 


\section{Revista do SELL}

v. $4, n^{\circ} .1$

ISSN: $1983-3873$

aluno. Por exemplo, "ser capaz de usar a própria inteligência" e "conseguir fazer-se entender e ser aceito pelos seres humanos" (exemplo 4) não se equivalem a priori: sua equivalência é instituída no/pelo próprio texto. Veja-se que "ser capaz de usar a própria inteligência" poderia instaurar outras correspondências como: conseguir resolver problemas, ser capaz de persuadir os outros etc. Nessa perspectiva, a única alternativa oferecida ao leitor é aceitar a interpretação dada pelo locutor.

A manifestação da pressuposição nos manuais didáticos

Conforme observamos anteriormente, "embora os pressupostos possam ser questionados e mesmo negados, eles são feitos para não o serem" (LARA, 2009, p. 6). A Podemos perceber que o locutor que veicula conteúdos pressupostos em seu discurso mostra, de antemão, sua posição de superioridade em relação ao interlocutor, instaurando o "quadro incontestável no interior do qual a conversação deve necessariamente inscrever-se", como postula Ducrot (1987, p. 20). Na análise do corpus, notamos que o autor do manual faz uso desse recurso, sobretudo para conferir aos enunciados um efeito de objetividade. Vejamos a seguir alguns exemplos de asserções e perguntas que veiculam pressupostos no manual PL. Em seguida, refletirmos sobre suas características e funções:

ex.6) Q.3- O que podemos fazer para não sermos manipulados pelos anúncios publicitários? (PL,2002, p.146)

ex.7) Q.3- Você acha válido e justo haver um único padrão de beleza para todas as pessoas? Por quê? (PL,2002, p.233)

ex.8) Q.3- Se a competição social é inevitável, como devemos lidar com ela para não sofrermos tanto? (PL,2002, p.102)

ex.9) Q.1- Como conciliar os estudos sem que se percam as fases naturais do desenvolvimento humano, como a infância e a adolescência? (PL, 2002, p.167) 


\section{Revista do SELL}

v. $4, n^{\circ} .1$

ISSN: $1983-3873$

No exemplo 6 notamos que enunciado deixa implícito que somos manipulados pelos anúncios publicitários (pressuposto), devendo 0 aluno/leitor concordar necessariamente com isso para poder dar continuidade à tarefa (responder à questão). Os exemplos 7 e 8 também veiculam os conteúdos pressupostos a) existe um único padrão de beleza para todos, e b) a competição social é inevitável. Em todas essas situações, coloca-se o aluno/leitor em situação de falta de escolha, já que não lhe são permitidas nem a recusa nem mesmo a dúvida sobre os conteúdos apresentados implicitamente. Acreditamos que a pressuposição assume a função de levar os interlocutores a raciocinar de acordo com um modelo pré-estabelecido, imposto pela escola. Essa função está presente nos enunciados que apresentam conteúdos pressupostos no manual italiano La lampada di Aladino. Vejamos:

ex.10) Q.5- Rifletti sui personaggi del racconto e spiega per iscritto quale di essi ti è risultato più simpatico e per quali ragioni.(LA, 2000, p. 127) (Reflita sobre os personagens da história e explique por escrito qual deles você mais gostou e as razões da escolha.)

ex.11) ex.) Q.4 - Quali sono i primi elementi che ci fanno capire che il testo, più che impaurire, vuol far sorridere? (LA, 2000, p. 190) (Quais são os primeiros elementos que nos fazem perceber que o texto, mais do que dar medo, quer fazer com que o leitor sorria?)

A função, assumida pelos pressupostos, de induzir o aluno-leitor a realizar a interpretação desejada pela escola é retratada claramente no exemplo10. Notamos que o interlocutor é obrigado a aceitar o que o locutor (autores do LD em conjunto) diz, sem questionamento ou discordância, não the cabendo admitir que não gostou de nenhum personagem, o que, evidentemente, é uma possibilidade a ser considerada quando se quer formar um leitor-crítico. Isso porque, se ele gostou "mais" de um, é porque gostou "menos" dos outros, mas, de toda forma, gostou deles, ou seja, a ênfase recai sobre (gostar) mais ou menos, mas não sobre gostar ou não gostar. Seria diferente se o locutor dissesse, por exemplo: "Você gostou de todos os personagens da história? Se a resposta for sim, diga de qual gostou mais." 


\section{Revista do SELL}

v. $4, n^{\circ} .1$

ISSN: $1983-3873$

Após esse breve olhar sobre as marcas de heterogeneidade do discurso, passaremos à análise contrastiva dos dois livros didáticos selecionados e às considerações finais de nossa investigação.

Análise contrastiva dos manuais analisados e considerações finais

$\mathrm{Na}$ análise realizada pudemos constatar que as paráfrases, tanto no manual brasileiro quanto no manual italiano, instituem equivalências no/pelo discurso (algumas inclusive questionáveis) e não cabe ao aluno contestá-las, sob pena de impedir a continuidade da atividade. Notamos que as paráfrases instituem uma equivalência entre dois termos, e têm o objetivo de induzir a interpretação do aluno/leitor. No manual brasileiro notamos que o fenômeno da paráfrase assume a função de auxiliar os aprendizes a interpretar o sentido de certos termos, apresentando-os em uma linguagem mais clara e acessível. Em ambos os manuais, as paráfrases projetam a imagem de um aluno "dependente de esclarecimentos".

No que se refere ao fenômeno da pressuposição, notamos que ele se presta a induzir o aluno-leitor a realizar a interpretação desejada pela escola, uma vez que as informações implicitadas (pressupostas) nas asserções e perguntas não deixam margem ao questionamento ou à discussão - são tidas como aceitas pelo locutor e pelo o interlocutor. Elas projetam a imagem de um aluno "cúmplice", pois não permitem a esse aluno a recusa, a negação e nem mesmo a dúvida sobre os dados que the foram, implicitamente, apresentados.

A partir das constatações acima elaboramos um quadro com a síntese das marcas de heterogeneidade e suas funções: 


\section{Revista do SELL}

v. $4, n^{\circ} .1$

ISSN: $1983-3873$

Quadro 1: Síntese das marcas de heterogeneidade presentes no corpus selecionado

\begin{tabular}{|c|c|c|c|}
\hline $\begin{array}{l}\text { Marcas de } \\
\text { heterogeneidade } \\
\text { do discurso }\end{array}$ & $\begin{array}{l}\text { Principal função } \\
\text { no livro didático }\end{array}$ & $\begin{array}{l}\text { Imagens } \\
\text { projetadas do } \\
\text { aluno-leitor }\end{array}$ & $\begin{array}{l}\text { Distinção entre } \\
\text { os dois manuais }\end{array}$ \\
\hline Paráfrases & $\begin{array}{l}\text { Apresentam } \\
\text { uma linguagem } \\
\text { mais próxima } \\
\text { dos aprendizes, } \\
\text { tornando mais } \\
\text { fácil a } \\
\text { apreensão do } \\
\text { significado de } \\
\text { certos termos. } \\
\\
\text { Estabelecem } \\
\text { uma relação de } \\
\text { equivalência } \\
\text { entre dois } \\
\text { enunciados ou } \\
\text { termos, } \\
\text { induzindo, de } \\
\text { certa forma, a } \\
\text { interpretação. }\end{array}$ & $\begin{array}{l}\text { Aluno } \\
\text { dependente de } \\
\text { esclarecimentos }\end{array}$ & Nenhuma \\
\hline Pressuposição & $\begin{array}{l}\text { Faz com que o } \\
\text { interlocutor } \\
\text { aceite as } \\
\text { informações } \\
\text { que Ihe são } \\
\text { passadas de } \\
\text { forma implícita } \\
\text { pelo locutor, } \\
\text { sem questioná- } \\
\text { las. }\end{array}$ & Aluno cúmplice & Nenhuma \\
\hline
\end{tabular}

Ao realizar uma análise quantitativa das perguntas e asserções que veiculam pressupostos notamos uma pequena recorrência em ambos os livros: aproximadamente $3 \%$ no manual brasileiro e $2 \%$ no manual italiano. O fenômeno da paráfrase também apresentou uma baixa recorrência: aproximadamente $5 \%$ em cada manual. Os resultados obtidos nos levam a considerar que o discurso dos manuais apresenta, de certa forma, 


\section{Revista do SELL}

v. $4, n^{\circ} .1$

ISSN: $1983-3873$

um número insignificante de atividades de leitura que tolhem a autonomia de raciocínio dos aprendizes. A partir dessas constatações, chegamos à seguinte conclusão:

As hipóteses a) de que as estratégias de ensino e as atividades de leitura propostas pelo manual italiano seriam mais eficazes se comparadas às do LD brasileiro; e b) que as competências requeridas dos alunos brasileiros durante os trabalhos com leitura são inadequadas para o desenvolvimento do seu raciocínio crítico não podem ser comprovadas, dado que o percentual de asserções e perguntas que veiculam conteúdos pressupostos e paráfrases é muito próximo (na média entre $2 \%$ e $5 \%$ ). A pequena recorrência dessas perguntas parece apontar para uma tendência a priorizar a formação de aprendizes questionadores diante dos textos propostos para leitura.

A partir do que foi exposto, acreditamos que seja necessária uma investigação mais profunda que traga resultados mais significativos para explicar por que os alunos brasileiros têm dificuldades de leitura, amplamente reveladas nas avaliações nacionais e internacionais, distanciando-se, nesse sentido, do alunado italiano, já que dois dos livros didáticos mais utilizados em ambos os países não apresentam tantas e tão relevantes diferenças que justifiquem desempenhos tão discrepantes.

Diante da não comprovação de nossas hipóteses, somos levados a propor novas hipóteses: uma delas seria a de que os professores brasileiros não estão suficientemente preparados - ou estão pouco preparados - para implementar as atividades propostas nos livros didáticos; a outra, a de que a imagem do aluno/leitor "ideal" projetada no LD está muito distante do aluno/leitor "real" de nossas escolas. Essas hipóteses, evidentemente, não se excluem.

A percepção desse frágil cenário educacional remete a um fenômeno que tem seu início nos anos 1950/1960, período em que uma grande massa de alunos, advindos das camadas populares, ingressa na escola. Conforme assevera Soares (2002, p. 165), nesse período

[...] começa a modificar-se profundamente o alunado: como consequência da crescente reivindicação, pelas camadas populares, do direito à escolarização, democratiza-se a escola, e já não apenas os "filhos-família", os filhos da burguesia, que povoam as salas de aula, são também os filhos dos trabalhadores - nos anos 60 , o número de alunos no ensino médio quase triplicou, e duplicou no ensino primário. 


\section{Revista do SELL \\ v. $4, n^{\circ} .1$ \\ ISSN: $1983-3873$}

Após a ampliação do acesso à educação, ocorreu, conforme a autora (SOARES, 2002, p. 165), a necessidade de recrutamento de um grande número de professores. Tal recrutamento, pouco seletivo, conduziu a um rebaixamento salarial e também a precárias condições de trabalho. Nesse período, os docentes que atuavam nas salas de aula não dispunham das ferramentas de trabalho adequadas para exercer a função e, muitas vezes, não possuíam nem mesmo a formação adequada para o cargo.

Atualmente um dos grandes desafios dos gestores do ensino é promover a capacitação dos professores - antigos e novos - que atuam nas escolas, tendo em vista que a formação desses profissionais gera uma melhoria direta na qualidade do sistema educacional. Podemos supor, nesse caso, que o profissional italiano é mais bem preparado do que o brasileiro, sendo inclusive mais valorizado do ponto de vista de salários e condições de trabalho.

Por outro lado, o alunado que passou a frequentar os bancos escolares em meados do século XX estava muito distante do "perfil" de aluno ideal. Apesar disso, a escola não adaptou seus métodos e materiais a esse público, o que causou uma grande quantidade de repetências e evasões, situação que ainda hoje, praticamente meio século depois, ainda não foi solucionada. No caso da Itália, um país dito de primeiro mundo, talvez o aluno/leitor ideal projetado no manual didático esteja muito mais próximo do aluno/leitor real do que no Brasil, o que pode explicar o sucesso de uns e o fracasso de outros.

Essas hipóteses, evidentemente, carecem de comprovação, o que aponta para a necessidade de um estudo mais amplo e profundo sobre o processo de ensinoaprendizagem no Brasil e na Itália. Portanto, o que fizemos no presente trabalho foi problematizar a questão da forma como a leitura é trabalhada nos manuais didáticos. Não nos restam dúvidas de que essas novas hipóteses para o fracasso dos alunos brasileiros, nas avaliações nacionais e internacionais, são apenas algumas explicações possíveis, no amplo leque de conjecturas que podem ser feitas. Esperamos, de qualquer forma, com a pesquisa desenvolvida, ter dado nossa contribuição - mesmo que modesta - para a discussão sobre esse tema tão complexo, mas, ao mesmo tempo, tão rico e tão permeado de possibilidades investigativas. 


\section{Revista do SELL}

v. $4, n^{\circ} .1$

ISSN: $1983-3873$

\section{Referências}

AUTHIER-REVUZ, Jacqueline. Palavras incertas: as não-coincidências do dizer. Campinas: Ed. UNICAMP, 1998.

BRANDÃO, Helena Nagamine. Introdução à Análise do discurso. Campinas: Ed. Unicamp, 2004.

CEREJA, William R.; MAGALHÃES, Thereza C. Português: linguagens, $7^{\text {ạ }}$ série. São Paulo: Atual, 2002.

DELL'ISOLA, Regina Lúcia P. Leitura: inferências e contexto sociocultural. Belo Horizonte: UFMG, 1991.

DUCROT, Oswald. O dizer e o dito. Campinas: Pontes, 1987.

KERBRAT-ORECCHIONI, Cathérine. Pressuposto/ Pressuposição. In: CHARAUDEAU, Patrick; MAINGUENEAU, Dominique (orgs.). Dicionário de análise do discurso. São Paulo: Contexto, 2004.

KOCH, Ingedore G.V. Argumentação e linguagem. São Paulo: Cortez, 1984.

LARA, Glaucia M. P. A imagem da língua portuguesa no discurso de sujeitos escolarizados e não-escolarizados. 1999. Tese. FFLCH/USP, São Paulo, 1999.

Examinando a pressuposição. In: SARAIVA, Maria Elizabeth F.; MARINHO, Janice Helena C. (orgs.). Estudos da língua em uso: da gramática ao texto. Belo Horizonte: Ed. UFMG, 2009. (no prelo).

MAINGUENEAU, Dominique. L'Analyse du Discours: introduction aux lectures de l'archive. Paris: Hachette, 1991.

Novas tendências em análise do discurso. Campinas: Ed. Unicamp,

1997.

MANDELLI, Fioretta; ROVIDA, Letizia. La lampada di Aladino 2. Milano: Editrice G. Principato, 2000.

MATÊNCIO, Maria de Lourdes M. M. Estudo da língua falada e aula de língua materna: uma abordagem processual da interação professor/alunos. Campinas: Mercado de Letras, 2001.

PETIT, Gérard. Paráfrase. In: CHARAUDEAU, Patrick; MAINGUENEAU, Dominique (orgs.). Dicionário de análise do discurso. São Paulo: Contexto, 2004.

PÊCHEUX, Michel. Semântica e discurso: uma crítica a afirmação do óbvio. Campinas: Ed. Unicamp, 1988. 


\section{Revista do SELL}

v. $4, n^{\circ} .1$

ISSN: $1983-3873$

Programa Internacional de Avaliação de Alunos, (PISA), 2000. Disponível em: http://www.inep.gov.br/download/internacional/pisa/PISA2000.pdf. Acesso em: 15/09/2008.

RIBEIRO, Nilsa B. Paráfrase e modalidade: um trabalho argumentativo na construção do sentido. In: 50은 SEMINÁRIO DO GEL, 2002, São Paulo. Resumo. Disponível em: http://www.gel.org.br/estudoslinguisticos/volumes/32/htm/comunica/cc062.htm. Acesso em: 10/07/2009.

Sistema de Avaliação da Educação Básica, (SAEB), 2001. Disponível em: http://www.inep.gov.br/download/saeb/2001/miolo novas perspectivas2001.pdf. Acesso em: 15/09/2008. 